\title{
Optimal and Computationally Efficient Priority- Based Routing and Wavelength Allocation Strategy Supporting Qos for High-Speed Transport Networks
}

\author{
Tarun Gupta, Amit Kumar Garg
}

\begin{abstract}
One of major optical network problem is to route and to assign the wavelength efficiently because of its wavelength reuse characteristics and information transparency. By utilizing the trade-off scheme between the blocking probability and setup time of the requested route, priority-based $R W A$ (PRWA) approaches has been studied for WDM networks by introducing a priority criterion which depends on calculation of hop counts and volume of the traffic. The simulation result shows that PRWA technique reduces both the blocking probability (approx. 20\%) as compare with non-priority based $R W A$ scheme and the average end to end delay near about (10 msec.) as compare with Adaptive routing (AR) at various traffic load conditions. This approach also results in cost-effectiveness as well as reduction in the complexity of the network in comparison to earlier reported techniques.
\end{abstract}

Keywords-WDM, Blocking probability, Priority queue, NSFNET, Routing and wavelength assignment.

\section{INTRODUCTION}

An optical network utilizing the concept of wavelength division multiplexing (WDM) which promises of providing the larger bandwidth demand for various challenging applications by allocating the bulk communication bandwidth of a fiber (approx.50Tb/s) into number of transmission channels with bandwidths (approx.10Gb/s) suitable with the electronic processing speeds of the destination users.

In all optical networks where, optical path is established between the wavelength routing nodes on all the available links is generally referred as Lightpath which is primarily essential for any network architecture and their constructive establishment is important to assign routes to the requested lightpath and to provide wavelengths on all available connections in order to maximize the performance metrics. This is basically the concept of RWA issues [2]. This problem enhances the efficiency of wavelength-routed optical networks where number of users can be adjusted and only a few users require to be rejected during congestion periods by the designed network.

Additionally, efficient assignment of wavelength is equally important in any communication model and it must be assigned in such a way that any two lightpaths which shares the common physical link not to use the same wavelength at any cost [1]. Furthermore, in networks where

Revised Manuscript Received on August 19, 2019.

Tarun Gupta, Ph.D. Scholar, DCRUST University, ECE Department, Haryana, India.(E-mail: tarungupta2605@gmail.com)

Amit Kumar Garg, Professor, DCRUST University, ECE Department, Haryana, India.(E-mail: garg_amit03@yahoo.co.in) conversion of wavelength [9] is absent or ignore, the concept of wavelength continuity constraint comes into the picture where same wavelength must be used for the available connections of the requested light paths.

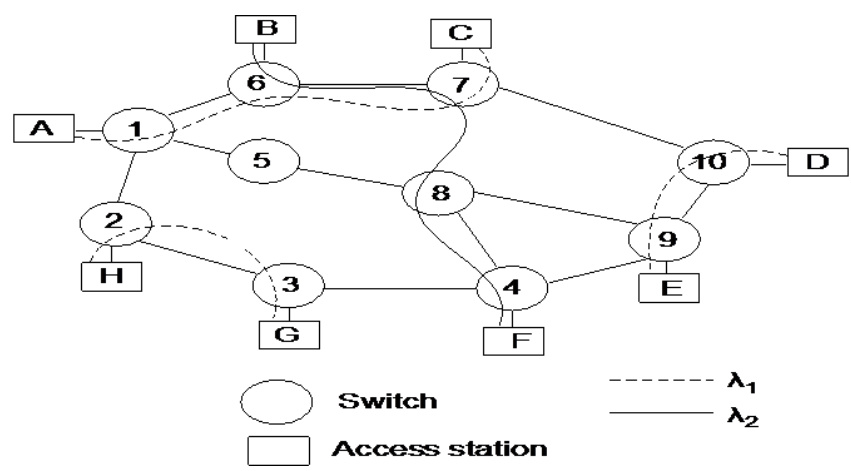

Fig. 1: Wavelength routed WDM network.

The above figure represents the lightpaths establishment between ( $s-d$ ) pairs by using two different wavelengths in an optical network. Here because of its wavelength continuity constraint, same wavelength must be used on each lightpath on all the available hops from source to destination path. Table 1 shows the lightpaths establishment between all the available s-d pairs.

Table 1: Summary of lightpaths establishment

\begin{tabular}{ccc}
\hline Source-Destination & Available wavelengths & Established lightpath \\
\hline A-C & $\lambda_{1}$ & A-1-6-7-C \\
B-F & $\lambda_{2}$ & B-6-7-8-4-F \\
H-G & $\lambda_{1}$ & H-2-3-G \\
D-E & $\lambda_{1}$ & D-10-9-E \\
\hline
\end{tabular}

The fiber link requests (H-G), (D-E) due to its reuse characteristics utilize the same wavelength which has been used by fiber link (A-C) i.e. $\lambda_{1}$. But the link requests $(\mathrm{B}-\mathrm{F})$ uses the other wavelength $\left(\lambda_{2}\right)$, because $(A-C)$ and $(B-F)$ uses the common link (6-7).

This research discusses most of the possible scenarios of prioritizing the link requests to improve the system performance and in order to achieve, requested lightpath is categorized in several groups based on priority which depends on number of hops count a request requires and capacity of the traffic [4-5]. This paper proposed RWA

Published By:

Blue Eyes Intelligence Engineering \& Sciences Publication 


\section{OPTIMAL AND COMPUTATIONALLY EFFICIENT PRIORITY-BASED ROUTING AND WAVELENGTH ALLOCATION STRATEGY SUPPORTING QOS FOR HIGH-SPEED TRANSPORT NETWORKS}

algorithm priority-based to minimize the blocking ratio and average setup time in the designed topology. The output of proposed PRWA approach than differentiate with the existing NPRWA schemes.

The remaining work is categorized as follows. Related work outlines in section 2 . Section 3 proposed PRWA approach and discussed in detail by using some examples. In section 4, outcomes of suggested scheme have been demonstrated. Lastly, concludes the research paper in section 5 .

\section{RELATED WORK}

Currently there are several suggested approaches which have been acquired such as greedy, evolutionary, fuzzy logic to solve the routing and wavelength assignment problem. D. Mishra presented various dynamic routing problems and differentiate it with the outcomes of the existing or similar algorithms where different approaches such as metaheuristic, fuzzy [11] showcase the grade of transmission aware algorithm. Y. Dong et al. [16] modeled a path length-based optimization algorithm assuming physical impairments, traffic grooming functionality and using the metaheuristic approach. Furthermore, Y. Dong et al. [19] discussed routing, wavelength assignment problem by introducing the dynamic functions which highlights path length-based optimization for all optical networks. Presenting the ant-based heuristics, M. Dell' Orco [17] studied discrete time model which estimates the time of travel based on the flow of traffic. In addition, Y.S. Kavian et al. [20] presented a logical approach where issues related to hop count and RWA propagation delay can be optimized. Further, D. Sousa [18] discussed other associated RWA problem by using evolutionary, IL programming algorithms.

Two conventional approach of routing and wavelength assignment have been discussed, static and dynamic RWA based on specific scenarios [3]. N. Charbonneau [12] proposed static routing assignment issues by using some heuristics approach. A.G. Rahbar [13] studied a literature review where the more focus given on dynamic impairment schemes. Additionally, the method associated with link characteristic is suggested by ignoring the statistical multiplexing effects which leads to face some crucial application limitations. A.N. Khan [14] studied a routingbased strategy to design or construct the large size networks where more s-d pairs are active parallelly.

To reduce the blocking ratio in all optical network, $\mathrm{P}$. Rajalakshmi et al. [15] proposed a dynamic wavelengthbased reassignment algorithms where continuous wavelength route is demanding and in order to fulfill, already established path needs to be reassigned to the other wavelengths which results to serves newer lightpaths for the same network configuration by considering minimal overlap schemes. In the proposed scheme, route for each established lightpath remains the same which means only the wavelength reassignment is performed.

In recent years, idea of prioritization has been integrated with RWA scheme for minimizing the blocking problems on
WDM networks. D.M. Shanan et al. [10] proposed an offline wavelength assignment based on priority where each traffic connection has been evaluated at source nodes in respect of the volume of the traffic enters and based on that prioritization of the wavelength can be accomplished. However, this proposed scheme not considering the other parameters like which type of traffic enters and number of hops count it requires and due to this the proposed scheme not met the expectation beyond a certain range.

The significant work accomplished on the existing researches but still few RWA related research seen where one can consider blocking probability and average setup time as a tradeoff approach to suitable with dynamic network state [6]. To overcome the challenges related with transmission speed and quality with the dynamically changed network requests, this paper researches a priority based RWA strategy by adding a value which depends on calculation of hops count and volume of the traffic of the requested connection for wavelength routed networks.

\section{PROPOSED PRWA APPROACH \& RESULTS}

To minimize the blocking probability in optical networks, PRWA scheme suggested where link requests are handled based on the priority order as per RWA approach. The calculation of the priority of each link request depends on the below two scenarios: (i) requested path either connects the s-d pair via direct path or indirect one (ii) capacity of the traffic. Considering these scenarios, higher priority would be given to the link request having direct path requests instead of link requests having indirect path [5]. Once the path is determined whether direct or indirect then the priority of the requests is structured in the descending order as per the volume of traffic and the goal is to minimize the BP and to improve the capacity utilization of a designed optical network.

In absence of wavelength conversion [9], the wavelength continuity constraint concept used where same wavelength must be used on available connections of the requested lightpath, but this may lead to a state where link requests cannot be matured because of unavailability of the required wavelengths, although the other wavelengths may be available for the designed network at that given point of time. Thus, if the link requests are calculated based on the priority order, blocking of link requests can be minimized to a large extent which enhances the outcomes of the simulated network.

The framework of suggested approach is shown in Fig. 2. First link requests arrive at the edge node of the network based on Poisson process which is random in nature. Then to evaluate their priority position the link requests can be passed through the Priority Queue [5]. Once the priority is assigned, link requests are served within the holding time $\left(t_{H}\right)$. Holding time is the average time a request waits in the priority queue before being served. If the request is not matured within that period, it is considered as a blocked request. To understand the significance of the proposed work along with its brief algorithm are discussed as below. 


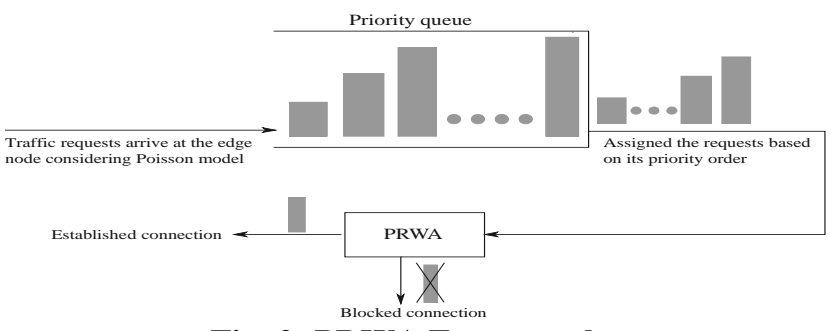

Fig. 2: PRWA Framework

Here, in Fig. 3 constructed a NSFnet topology contains 6 nodes, 9 two-way fibre links and all link consists of wavelengths $\left(\lambda_{1}\right.$ and $\left.\lambda_{2}\right)$. In Table 2 , five lightpath requests considered based on volume of the traffic. Once the algorithm is applied to the designed topology, ordered sets of lightpath requests are formed in two groups $\left(\mathrm{LR}_{1}\right.$ and $\mathrm{LR}_{2}$ ) in such a way that $\mathrm{LR}_{1}=\left\{\operatorname{lr}^{1,5}, \operatorname{lr}^{1,6}, \operatorname{lr}^{1,2}\right\}$ and $\mathrm{LR}_{2}=$ $\left\{1 r^{1,4}, \operatorname{lr}^{1,3}\right\}$. In Table 3 , lightpath request is established based on the priority of the request.

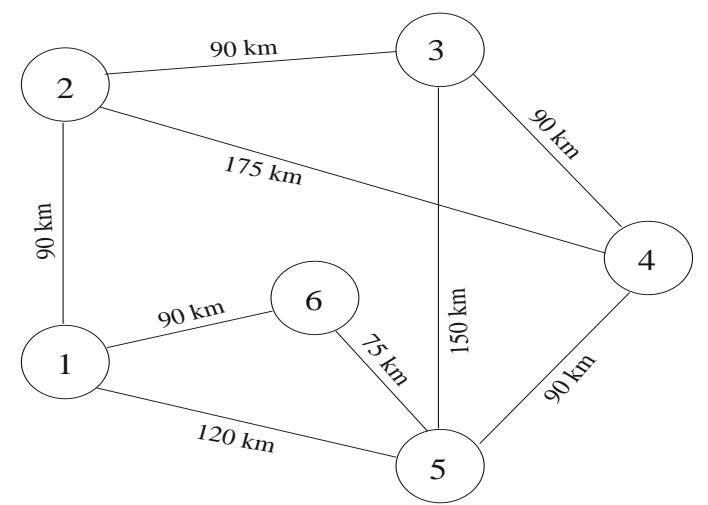

Fig. 3: 6-nodes NSFNET topology

\begin{tabular}{c|c}
\hline Lightpath requests & Traffic (Kops) \\
\hline $\operatorname{Ir}^{1,4}$ & $1,20,000$ \\
\hline $\operatorname{Ir}^{1,2}$ & 10,000 \\
\hline $\operatorname{Ir}^{1,5}$ & $1,30,000$ \\
\hline $\operatorname{Ir}^{1,6}$ & 40,000 \\
\hline $\operatorname{Ir} 1,3$ & $1,00,000$
\end{tabular}

Table 2: Lightpath requests vs volume of traffic

\begin{tabular}{c|c}
\hline $\begin{array}{l}\text { Groomed connection } \\
\text { requests }\end{array}$ & Priority orde \\
\hline $\operatorname{Ir} 1,5$ & $1^{\text {st }}$ \\
\hline $\operatorname{Ir} 1,6$ & $2^{\text {nd }}$ \\
\hline $\operatorname{Ir}^{1,2}$ & $3^{\text {rd }}$ \\
\hline $\operatorname{Ir} 1,4$ & $4^{\text {th }}$ \\
\hline $\operatorname{Ir} 1,3$ & $5^{\text {th }}$
\end{tabular}

Table 3: Connection requests vs prioritization

\section{PERFORMANCE ANALYSIS}

To examine the outcomes of RWA algorithms in respect of BP, considers First-Fit (FF) WA approach as its offers lesser blocking probability and lower evaluation complexity among all existing schemes [1].

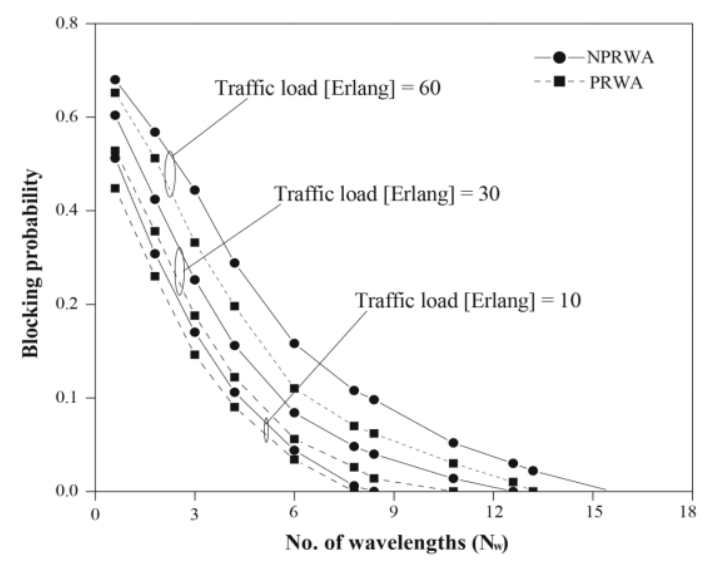

Fig. 4: Blocking probability vs $\mathrm{N}_{\mathrm{W}}$ on priority and nonpriority based schemes by using different traffic load.

Fig. 4 shows BP vs number of wavelengths $\left(\mathrm{N}_{\mathrm{W}}\right)$ considering the Priority and non-priority based RWA approaches for different traffic load by using NSFNET topology. It is clearly seen from the simulation results that by implementing the suggested scheme, there is a reduction appears in BP (approx. 20\%) as compare with non-priority based RWA scheme at various traffic load conditions. The result also shows as the traffic load increases, rate of increase in blocking probability is higher.

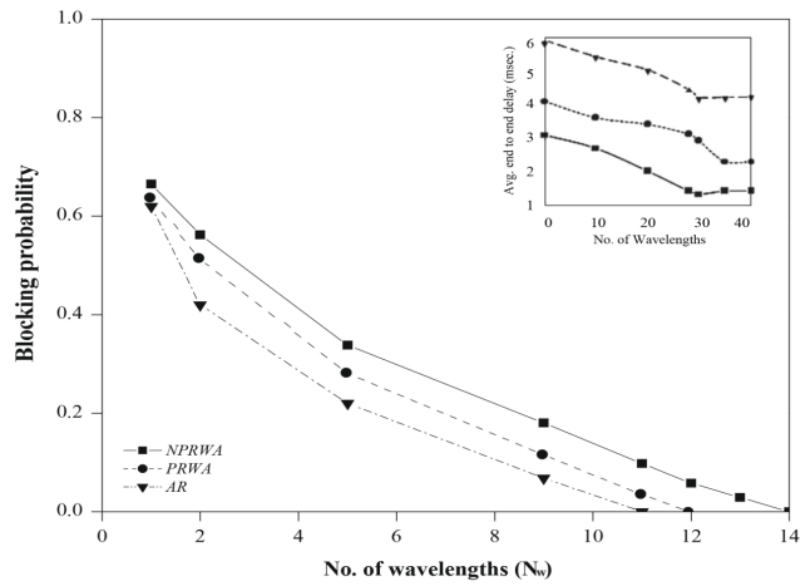

Fig. 5: Blocking probability vs $\mathrm{N}_{W}$ on various RWA algorithms in NSFNET topology.

Fig. 5 shows BP versus no. of wavelengths for various RWA algorithms like NPRWA, PRWA, AR (Adaptive Routing) [7-8]. The result reveals that the BP reduces when there is increase in available wavelengths because of more lightpaths have been setup, but in all available algorithms rate of reduction in $\mathrm{BP}$ in case of $\mathrm{AR}$ is more than other existing routing algorithms and its due to the fact that in this routing algorithm all the best possible paths are considered between s-d pair based upon the link-state information. Furthermore, simulation result reveals that BP for proposed PRWA is (approx. 20\%) less than the existing NPRWA [5] although it's comparatively high in comparison of AR. But on the other hand it can also be observed, on AR higher

Published By:

Blue Eyes Intelligence Engineering

\& Sciences Publication

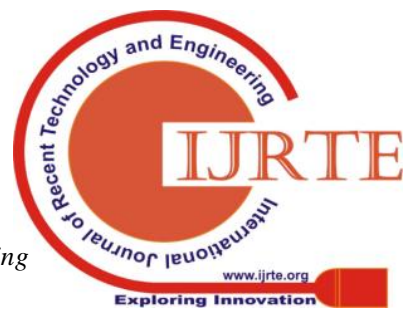




\section{OPTIMAL AND COMPUTATIONALLY EFFICIENT PRIORITY-BASED ROUTING AND WAVELENGTH ALLOCATION STRATEGY SUPPORTING QOS FOR HIGH-SPEED TRANSPORT NETWORKS}

average setup time (approx. 10msec.) requires as compared to PRWA and other existing algorithms and its mainly due to AR algorithm considers all the best possible paths and as count of the routes increases, average end to end delay increases as well (which is shown in the inner graph of above figure).

\section{CONCLUSION}

The paper examined priority-based RWA approach to minimize the blocking ratio in all optical networks. The priority-based establishment of lightpath request is evaluated which depends on the fact whether the requested path in between source-destination pair is the single hop link or multi-hop path and secondly the capacity of the requested traffic. Once the priority is assigned, the proposed scheme serves the optical path requests accordingly. The outcome reveals that BP using the proposed approach is less than that of using the non-priority based RWA approach. Adaptive routing (AR) using First-Fit approach provides the better results in respect of $\mathrm{BP}$, but meanwhile setup time requires for $\mathrm{AR}$ is much higher in comparison with the discussed scheme. The proposed scheme provides the trade-off between the two-performance metrics which will enhance the overall system productivity in respect of blocking probability and the average end to end delay of the requested route.

\section{REFERENCES}

1. P.H.G. Bezerra, A.J.F. Cardoso, C.R.L. Frances, Performance evaluation of algorithms for wavelength assignment in optical WDM networks, IJCSNS vol. 10, no. 1, pp. 130-136, 2010.

2. B.C. Chatterjee, N. Sarma, P.P. Sahu, Review and performance analysis on routing and wavelength assignment approaches for optical networks, IETE Tech. Rev. vol. 30, no. 1, pp. 12-23, 2013.

3. Neal Charbonneau. Static Routing and Wavelength Assignment for Multicast Advance Reservation in All-Optical Wavelength-Routed WDM Networks. In IEEE/ACM Transactions on Networking (TON) vol. 20, no. 1, pp. 15-20, 2012.

4. H.-P. Schwefel, L. Lipsky, Impact of self-similar On/Off traffic on delay in stationary queuing models, Performance Evaluation, vol. 43, no. 4, pp. 203-221, March 2001.

5. B.C. Chatterjee, N. Sharma, P.P. Sahu, A heuristic prioritybased wave-length assignment scheme for optical networks, Optik vol. 123, no. 17, pp. 1505-1510, 2012.

6. D. Banerjee, B. Mukherjee, Wavelength-routed optical networks: Linear formulation, resource budget trade-offs and a reconfiguration study, IEEE/ACM Transactions on Networking, vol. 8, no. 9, pp. 598-607, Oct. 2000.

7. E. Karasan and E. Ayanoglu, "Effects of Wavelength Routing and Selection Algorithms on Wavelength Conversion Gain in WDM Optical Networks," IEEE/ACM Transactions on Networking, vol. 6, no. 2, pp. 186-193, April 2008.

8. Asuman E. Ozdaglar and Dimitri P. Bertsekas Routing and Wavelength Assignment in Optical Networks. In Networking, IEEE/ACM Transactions, vol. 11, no. 2, pp. 220-230, 2003.

9. G Shen, T.H Cheng, S.K Bose, C Lu, T.Y Chai, H.M.M Hosseini. Approximate analysis of limited-range wavelength conversion all-optical WDM networks. In Computer Communications; vol. 24, no. 10, pp. 126-130, 2001.

10. Shan, D.M., Chua, K.C., Phung, M.H., Mohan, G.: Prioritybased offline wavelength assignment in OBS networks. IEEE Trans. Communications: vol. 56, no. 10, pp. 1694-1704, 2008.

11. D. Mishra and U. Bhanja, "FWM Aware Fuzzy Dynamic Routing and Wavelength Assignment in Transparent Optical
Networks", International Journal of Electrical, Electronic and Communication Engineering, vol. 9, issue 8, pp. 981-990, 2015.

12. N. Charbonneau and V.M. Vokkarane, "Static Routing and Wavelength Assignment for Multicast Advance Reservation in All-Optical Wavelength-Routed WDM Networks", IEEE/ACM TRANSACTIONS ON NETWORKING, vol. 20, issue 1, pp. 1-14, 2012.

13. A.G. Rahbar, "Review of Dynamic Impairment-Aware Routing and Wavelength Assignment Techniques in AllOptical Wavelength Routed Networks", IEEE COMMUNICATIONS SURVEYS \& TUTORIALS, vol. 14 issue 4, pp. 1065-1089, 2012.

14. A.N. Khan and P. Saengudomlert, "Design based routing and wavelength assignment in WDM networks using link-based multiplexing gain", Optical Switching and Networking, vol. 15, no. 10, pp. 111-120, 2015.

15. Rajalakshmi, P., Jhunjhunwala, A. Wavelength reassignment algorithms for all-optical WDM backbone networks. Opt. Switch. Networks, vol. 4, no. 3, pp. 147-156, 2007.

16. X. Wang, M. Brandt-Pearce, and S. Subramaniam, "Distributed grooming, routing, and path length-based wavelength assignment for dynamic optical networks using ant colony optimization", IEEE/OSA Journal of Optical Communications and Networking, vol. 6, issue 6, pp. 578589, 2014

17. M. Dell' Orco, M. Marinelli, and M.A. Silgu, "Bee Colony Optimization for innovative travel time estimation, based on a mesoscopic traffic assignment model", Transportation Research Part C: Emerging Technologies, vol. 66, issue 2, pp. 48-60, 2016.

18. [18] A. de Sousa, C.B. Lopes, and P. Monteiro, "Lightpath Admission Control in Dynamic Optical Transport Networks", Electronic Notes in Discrete Mathematics, vol. 52, issue 8, pp. 205-212, 2016

19. Y. Dong, S. Zhao, H. dan Ran, Y. Li, and Z. Zhu, "Routing and wavelength assignment in a satellite optical network based on ant colony optimization with the small window strategy", IEEE/OSA Journal of Optical Communications and Networking, vol. 7, issue 10, pp. 995-1000, 2015.

20. Y.S. Kavian, A. Rashedi, A. Mahani, and Z. Ghassemlooy, "Routing and wavelength assignment in optical networks using Artificial Bee Colony algorithm", Optik - International Journal for Light and Electron Optics, vol. 124, issue 12, pp. $1243-1249,2013$ 